\title{
MAIN DIRECTIONS OF IMPROVEMENT OF PEDAGOGICAL TECHNOLOGIES IN HIGHER ECONOMIC SCHOOL
}

\author{
Dmitry Vlasov $^{1 *}$ and Alexander Sinchukov ${ }^{2}$ \\ ${ }^{1}$ Prof, Plekhanov Russian University of Economics, RUSSIA, Financial University under the \\ Government of the Russian Federation, RUSSIA, DAV495@gmail.com \\ ${ }^{2}$ Prof, Plekhanov Russian University of Economics, RUSSIA, AVSinchukov@gmail.com \\ ${ }^{*}$ Corresponding Author
}

\begin{abstract}
This article presents the directions of improving pedagogical technologies in a higher economic school in the context of the introduction of new digital technologies and digital tools. At the same time, special attention is paid to the application of pedagogical technologies and design activities to the mathematical preparation of the future bachelors and masters of economics. Within the framework of each of the presented areas, the most significant tasks are identified, solutions of which are associated with improvement of the quality of professional training of graduates of a higher economic school. The author notes the demand for the system of pedagogical technologies of V.M. Monakhov for the modernization of methodological systems for teaching mathematical disciplines in the higher economic school and indicates the need for their adaptation, taking into account the applied and research capabilities of new digital technologies and digital tools. In order to clarify the boundaries of the effectiveness of the integration of digital and pedagogical technologies, the following research areas are identified and characterized in the article: Teaching Methods, Learning Content, and Methodological Features of Teaching. Experimental work and generalizations of the pedagogical theory made it possible to identify the directions of improving pedagogical technologies in the higher economic school. Among them: the development of ideas about the modern theory of teaching and the contentmethodological features of the design and implementation of the model of the educational process in the new conditions of digitalization; the formation of philosophical and methodological foundations for conducting modern didactic research on the development of the professional competence of the future bachelor of economics by means of mathematical disciplines, to a greater extent ensuring the evidence and objectivity of the identified methodological patterns and recommendations for their use in the educational process; creation of a model for the development of digital educational systems in the context of the introduction of new digital technologies and digital tools and clarification of its predictive potential; intellectualization, automation and commercialization of educational systems in the context of the widespread introduction of new digital technologies and digital tools, taking into account the global technologization and digitalization of the higher economic school and the improvement of the mechanisms for improving the qualifications of teachers of the higher economic school through the dissemination and commercialization of pedagogical technologies.
\end{abstract}

Keywords: pedagogical technology, digitalization, modelling, model representations, logical structure, mathematical training, integration. 


\section{INTRODUCTION}

In modern conditions of digitalization of the economy and economic research, the system of higher economic education requires revision of the quality of professional training of the future economist. A strategic task, the solution of which is associated with improving the quality of professional training of a future economist at an economic university, is the task of adapting already well-proven pedagogical technologies to new conditions [Okunkova E., 2018]. The practice of introducing pedagogical technologies into the process of professional training of future economists in the framework of teaching mathematical disciplines at the Russian University of Economics after G.V. Plekhanov demanded the allocation and consideration of directions for improving pedagogical technologies used at all stages of educational and cognitive activities of students of economic bachelor's degree. To date, we have found and carried out an instrumental implementation of the idea of integrating digital and pedagogical technologies. The problem of improving pedagogical technologies in a higher economic school can be associated with such pedagogical categories as "Methods of Teaching ", "Content of Teaching ", "Methodological Peculiarities of Teaching." Let's reveal the essence of each of them, focusing on the evolution of classical pedagogical categories under the influence of the technological approach. "Methods of Teaching ", in the context of the use of problem-search learning, active learning with an optimal combination of frontal and individual work of students of economic bachelor's degree, the level of justification for the choice of one or another teaching method depending on the content and methodological characteristics of the academic topic, the appropriateness of application "Content of Learning" - the level of methodological adaptation and logical sequence of disclosure of the mathematical objects and concepts studied, understanding the possibilities of digital technologies in the context of organizing group work of students with elements of the content of mathematical training, the use of mechanisms for activating the attention and concentration of students when working with the content of mathematical disciplines, identifying and taking into account in the educational process of intra-subject and inter-subject connections between elements of the content of education, which are of the greatest importance for the development of professional competence of the future economist. "Methodological peculiarities of teaching" - the degree of adequacy of the teacher's choice of educational material at all stages of the organization of educational and cognitive activities of students, the use of practice-oriented tasks with different formulations for students in the main areas of mathematical training (perform a comparative analysis, prove, build a model, justify, suggest alternative, etc.), aimed at the implementation of the applied orientation of the designed and subsequently implemented educational process. The number of included practical tasks for the technical development of basic techniques and methods, as well as the completeness of the bank of technological diagnostics to check the level of formation of key and professional competencies of future economists.

\section{LITERATURE REVIEW}

Considering the penetration of digital technologies at all levels of professional and pedagogical activity of a teacher of a higher economic school, the demand and widespread use of V.M. Monakhov's pedagogical technologies [Bahtina O.I., 2018], as well as the system-forming role of pedagogical technologies in the evolution of methodological teaching systems educational disciplines, identifying areas for improving pedagogical technologies seems to be an important pedagogical task. In addition, we consider it necessary for each area of improving pedagogical technologies in a higher economic school to detail and analyze actual problems that are of particular importance in the context of teaching applied mathematical disciplines for bachelor of economics students. It should be noted that the methodological system of applied mathematical training has been comprehensively considered within the framework of the works by:[MukhanovS.A., 2019, [Mukhanov S.A., 2019, Sukhorukoval.V., 2018], including an option of its implementation based on the communicative-activity approach [Vlasov Dmitriy, 2019]. Within the framework of this article, the practical results obtained by the authors in the development of a methodological concept, design of methodological support based on it, and teaching of the academic disciplines "Higher Mathematics", "Theory Probability and Mathematical Statistics", "Theory of Game ", "Theory of Risk" will be summarized [Voronova, T. A., 2020], "Theory of Decision", "Insurance Mathematics" [Sukhorukoval.V., 2018], "Theory of Optimal Control", "Econometrics (basic level)", "Econometrics (advanced level)" [KarabutovN.N. , 2016]. Considering the technological and projected components of pedagogical activity, the authors point out the need to study the educational environment [IvanovaE.V., 2019], improvement of approaches to the development of educational programs [Vachkovl.V., 2016], take into account the results of interdisciplinary research [AndruhinaL.M ., 2020, Osmolovskaya I.M., 2018]. Much attention is paid to the design of the content of the mathematical training of the future economist, associated with the development 
of his professional competence. So, he will indicate the works [Ahmetović E., 2018, GoodyearP. 2020, HedgesL.V., 2007]. However, the technological procedures for designing the content of education, developed to date in the Higher School of Economics, require reconsideration from the standpoint of the introduction of new digital technologies and digital tools.

\section{RESEARCH METHODOLOGY}

The theory of pedagogical technologies (V.M. Monakhov, A.I. Nizhnikov, E.I. Smirnov, S.K. Islamgulova), the theory of pedagogical design (S.A. Mukhanov), Radionov V.E., Zair-Bek E.S.), quantitative methods and mathematical modeling in the social and economic spheres (Sukhorukova I.A., Tatarnikov O. V., Tikhomirov N.P.) became the methodology for improving pedagogical technologies in the higher economic school in our study.

Work to improve pedagogical technologies in Higher School of Economics, conducted by the authors on the basis of the Russian University of Economics after G.V. Plekhanov and the Financial University under the Government of the Russian Federation demanded the involvement of the modern theory of digitalization of the educational process, adaptation of pedagogical technologies by V.M. Monakhov (technologies for designing the educational process, technologies for designing a methodological teaching system, technologies for designing individual and group educational trajectories, technologies for designing a full cycle textbook, etc.), as well as providing organizational and didactic conditions for the practical implementation of the integration of digital and pedagogical technologies.

\section{PRACTICAL IMPORTANCE, PROPOSALS AND IMPLEMENTATION RESULTS}

Within the framework of this section, we will present five directions (areas) of improvement of pedagogical technologies in a higher economic school, highlighting for each of them relevant pedagogical tasks. The practical significance of solving the presented pedagogical problems lies in improving the quality of professional training of future bachelors and masters of economics, developing a new didactic toolkit for a teacher of a higher economic school, providing professional growth and high digital culture, improving the system of continuous economic education in Russia in the direction of increasing its availability and efficiency.

Direction 1. Development of ideas about modern learning/teaching theory and the content-methodological features of the design and implementation of the educational process model in the new conditions of digitalization. These ideas are necessary to improve the quality of professional training of future economists at the University of Economics, the purposeful development of his key and professional competencies, including those related to quantitative methods and mathematical modeling. Note that model representations of modern teaching theory and the content-methodological features of the design and implementation of the model of the educational process should take into account the didactic effects of the introduction of new digital technologies and digital tools, taking into account their methodological adaptation. According to earlier studies [Vlasov2018;], pedagogical design should be considered as the most important condition for the creation and development of pedagogical systems. The uniqueness and relevance of the apparatus of pedagogical design in the context of the implementation of the model of the educational process in the new conditions of digitalization consists in the fact that it allows the teacher to approach the process of goal setting in a new way, in particular to form elements of advanced pedagogical thinking, a new design culture. Also, developed ideas about the content and methodological features of design make it possible to form the content of education based on the principle of advanced reflection of scientific knowledge. No less important for the implementation of the model of the educational process in the new conditions of digitalization is the predictive potential of pedagogical design, which determines the prospective state of the projected pedagogical objects.

Direction 2. Formation of philosophical and methodological foundations for conducting modern didactic research on the development of professional competence of a future bachelor of economics by means of mathematical disciplines, to a greater extent providing evidence and objectivity of the identified methodological patterns and recommendations for their use in the educational process. It is important to note that the didactic results obtained on the basis of new philosophical and methodological foundations (communicative-activity approach, the integration of digital and pedagogical technologies, the technology of designing the zones of the student's proximal development, etc.) should be correlated with the possible didactic results obtained on the basis of traditional methods. learning.

Research of mechanisms for strengthening the applied professional orientation of the design activities of teachers of a higher economic school in the context of digitalization of the economy and economic research. 
Clarification of the applied and research potential of new digital technologies and digital tools, serving as a modern didactic toolkit for the design activities of a teacher. Improving the techniques and methods of mathematical modeling of pedagogical objects in the context of the integration of digital and pedagogical technologies, the purpose of which is advanced model concepts of pedagogical objects, which include: the educational process, the methodological training system, an individual educational trajectory, a group educational trajectory, a digital educational resource, a zone of proximal development student, etc. It is necessary to point out the essential role of techniques and methods of mathematical modeling of pedagogical objects for the development of pedagogical technologies, as well as the predictive power 4 mathematical modeling and quantitative methods to create a new digital educational environment for an economic university, aimed at increasing the competitiveness of the graduate.

Direction 3. Creation of a model of the development of digital educational systems in the context of the introduction of new digital technologies and digital tools and clarification of its predictive potential. Formalization of the process of development of digital educational systems by highlighting parameters and reflecting the most significant connections and relationships within the evolving educational systems. Note that formalization as an obligatory stage in modeling the development of digital educational systems requires the adaptation of the methodology of methods and techniques of computational experiment widely used in humanitarian research. The solution to this problem is associated with the phenomenon of the mass character of higher education and the global technologization of the pedagogical activity of a teacher of a higher economic school. Thus, the formalization of the process of development of digital educational systems should provide the lecturer of a higher economic school with the necessary technological tools and modern digital didactic arsenal, adequate to the set tasks of developing the professional competence of the future economist.

The task of developing and introducing into the practice of teaching mathematical disciplines at a higher economic school of the important innovative concept "Working field" of a teacher-researcher, which involves the use of the potential of mathematical modeling of the main pedagogical objects in digital didactics. Note that the clarification of the concept of "Working field" and filling it with specific content, taking into account the content and methodological features of various mathematical disciplines studied by future bachelors and masters of economics is impossible without creating the necessary methodological and technological tools for creating and constructing mathematical models of the main pedagogical objects in demand in practice of professional training of future economists.

Direction 4: Intellectualization, automation and commercialization of educational systems in the context of the widespread introduction of new digital technologies and digital tools, taking into account the global technologization and digitalization of the Higher School of Economics. Creation of SMART textbooks on the main applied mathematical disciplines for the professional training of future bachelors, a distinctive feature of which is the ability to update the content context and reconfigure the initial methodological logic of the formation of professionally significant concepts. Let us note the demand for the technological procedure for dosing educational material for the creation of SMART textbooks and other digital educational resources that allow us to focus on the development of innovative components of the professional competence of future economists related to the quantitative substantiation of decisions.

Development of didactic theory and its corresponding instrumental pedagogical technology, ensuring the creation of a professionally oriented system of tasks and exercises. When creating a professionally oriented system of tasks and exercises in mathematical disciplines studied by future economists, special attention should be paid to the process and logic of the formation of the concepts "Modeling", "Model", "Formalization", "Optimization", "Optimum", "System", " Matrix "," Vector "," Ratio ". An important didactic condition for creating an effective system of tasks and exercises is the establishment of relationships between the content of educational disciplines of applied mathematical training of future economists with the content of the projected system of tasks and exercises, taking into account the instrumental capabilities of new digital technologies and digital tools. No less important is the clarification of the mechanisms for determining the dosage levels of tasks and exercises for the substituted micro-goal, which is implemented within the framework of the corresponding didactic module.

Direction 5. Improving the mechanisms of advanced training of teachers of the higher economic school through the dissemination and commercialization of pedagogical technologies. A study of the features, conditions and directions of the evolution of the professional and pedagogical functions of a teacher of a higher economic school in the context of the integration of digital and pedagogical technologies under the influence of the digitalization of the economy and economic research. The solution to this problem is associated with an urgent methodological problem of the development and implementation of adapted 
pedagogical technologies, taking into account the applied and research potential of new digital tools, including for automation of the processing of individual and group results of technological diagnostics, allowing the teacher of a higher economic school to make timely and adequate management decisions to correct the ongoing project of the educational process.

Organization of technological monitoring to improve the qualifications of teachers of a higher economic school through the dissemination and commercialization of pedagogical technologies. The solution to this problem involves the formation of teachers' competencies in designing their own (author's) model of the educational process, developing a proposal for improving their own professional and pedagogical activities, taking into account the content and methodological features of academic disciplines. An important role in the context of the evolution of the professional and pedagogical functions of a teacher of a higher economic school is played by the development of new technological documentaries, in particular, the formation of skills in constructing the educational process with predetermined results (key and professional competencies of students of economic bachelor's degree) in the form of technological pictures of information maps of practical classes.

\section{IMPLEMENTATION RESULTS}

The analysis of the results of the implementation of the technological approach and the instrumental implementation of pedagogical design in the context of the integration of digital and pedagogical technologies was carried out in several directions.

Thus, an increase in flexibility and variability of the educational process in mathematical disciplines was noted by $32 \%$ of students, satisfaction with the organization of the educational process in mathematical disciplines increased by $20 \%$. A decrease in anxiety in the study of mathematical disciplines was revealed in $65 \%$ of undergraduate economics students, and more than $30 \%$ of the surveyed undergraduate economics students indicated an improvement in the quality of the educational process by strengthening the applied focus and integration of digital and pedagogical technologies. The opportunity to choose an individual educational trajectory at the first stage of introducing a technological approach to the professional training of a future economist was used by $13 \%$ of students, at the second stage already more than $40 \%$ of students. There is also a positive trend in the formation of subject competencies in the field of mathematical modeling and quantitative methods, revealed through a series of technological diagnostics: solving mathematical problems (socio-economic content) that do not involve the use of digital technologies: basic level (growth of about $20 \%$ ), advanced level (growth of about $9 \%$ ); solving mathematical problems that do not involve the use of digital technologies: basic level (growth of about 15\%), advanced level (growth of about $5 \%$ ). Thus, the practical implementation of the presented directions for improving pedagogical technologies allows us to make about their fundamental effectiveness in the higher economic school. Note that in the next stage of studying the possibilities of the technological approach in the practice of professional training of future bachelors and masters of economics, in addition to using the method of expert assessment and survey, we will use quantitative methods (statistical criteria) that allow us to more subtly assess the boundaries of the effectiveness of the author's methodological approaches and technologies.

\section{CONCLUSIONS: DISCUSSION OF THE RESULTS}

The work on the creation, implementation and adaptation of pedagogical technologies, as well as the analysis of best practices for the design of pedagogical objects, allowed us to formulate several organizational and didactic principles of mathematical training, which are essential for improving the quality of professional training of future economists in the context of the introduction of new digital technologies and digital tools. This system of didactic principles of mathematical training of the future bachelor of economics was developed on the basis of the achievements of the theory of pedagogical technologies by V.M. Monakhov: "The didactic principle of multicomponent"; "The didactic principle of adaptability (flexibility)"; "The didactic principle of integrity and consistency"; "The didactic principle of openness" ; "The didactic principle of variability"; "The didactic principle of operational control of the results"; "The didactic principle of interactivity"; "The didactic principle of applied amplification."

Thus, the direction of improving pedagogical technologies in a higher economic school implies the design of the educational process and methodological systems of education, taking into account the requirements of professional and state standards, ensuring the focus of the educational process on the development of innovative components of the professional competence of the future economist and affects the cognitive, communicative and regulatory activities of undergraduate economics students. 


\section{REFERENCE LIST}

Ahmetović E., Bećirović S., Dubravac V. (2020) Motivation, anxiety and students' performance // European Journal of Contemporary Education. 2020. T. 9. № 2. C. 271-289.

Andryukhina L.M., Sadovnikova N.O., Utkina S.N., Mirzaakhmedov A.M. (2020) Digitalization of vocational education: perspectives and invisible barriers / Education and science. 2020. T. 22. No 3 (172). P. 116-147.

BakhtinA O.I., Monakhov V.M. (2018) Formation of a new view on informatization and scientific and technological development of modern theory of learning / Herald of Moscow University. Episode 20: Educational Education. 2018. No 2. S. 60-77.

Goodyear P. (2020) Design and co-configuration for hybrid learning: theorising the practices of learning space design // British Journal of Educational Technology. 2020. T. 51. № 4. C. 1045-1060.

Hedges L.V. (2007) Effect sizes in cluster-randomized designs // Journal of Educational and Behavioral Statistics. 2007. T. 32. № 4. C. 341-370.

Ivanova E.V., Vinogradova I.A., S.A. S.A. (2019) Study of the school's educational environment in the context of ensuring equal access to quality education / Education and science. 2019. T. 21. No 7. P. 69-89.

Karabutov N.N., Feklin V.G. (2016) Adaptive identification of systems with distributed lags // Journal of Mathematical Sciences. 2016. T. 216. № 5. C. 649-666.

Mukhanov S.A., Bogdanov M.R., Mukhanova A.A. (2020) Designing an Electronic Training Course on Differential Equations and Its Application in the Framework of the Blended Learning Concept. 10.2991/aebmr.k.200502.130

Mukhanov, S.A. \& Arkhangelsky, A.I. \& Mukhanova, A.A. (2019) Differentiated and individualised teaching mathematics to students of technical universities. 10.2991/mtde-19.2019.120.

Okunkova E., Kuznetsova E., Karasev P. (2018) Essential problems identification of staffing needs of innovative economy /5th International Multidisciplinary Scientific Conference on social sciences and arts SGEM 2018. Conference proceedings. 2018. C. 353-360.

Osmolovskaya I.M., Krasnova L.A. (2018) Learning from the position of interdisciplinary research / Education and science. 2018. T. 20. No. 8. S. 9-27.

Sukhorukova I.V., Chistiakova N.A. (2018) Economic regulation and mathematical modeling of insurance product cost, in Regional Science Inquiry, Vol. X (2), pp. 195-203, 2018.

Sukhorukova I.V., Chistyakova N.A. (2018) Methodical aspects of actuarial mathematics teaching. Astra Salvensis. 2018. T. 6. C. 847-857.

Tikhomirov N., Tikhomirova T., Khamitov E., Ponomarev V. (2017) Models of assessment of the influence of insurance assets securitization on stability of mutual insurance societies // European Research Studies Journal. 2017. Vol. XX. Issue 2B. Pp. 321-333.

Tikhomirov N.P., Tikhomirova T.M., Khamitov E.M. (2018) Methods of assessing the optimal procedure for forming mutual insurance funds // International Journal of Civil Engineering and Technology. 2018. Volume 9. Issue 12. Pp. 55-61.

Vachkov I.V., Vachkova S.N., Voropayev M.V., S.A., Remorenko I.M. (2016) Comparative analysis of assessments by teachers and parents of public participation in the development of basic educational programs / Psychological science and education. 2016. T. 21. No. 4. S. 19-31.

Vlasov D., Sinchukov A. (2018). Trends in the development of economic education in the conditions of new industrialization. Advances in Social Science, Education and Humanities Research, vol. 240 10.2991/sicni-18.2019.64

Vlasov Dmitriy, Sinchukov Alexander (2019) Trends in the development of economic education in the conditions of new industrialization 10.2991/sicni-18.2019.64

Voronova, T. A.; Golubtsova, E., V; Maksimov, D. A.; Novikova, E. S.; Ponomareva, N., V The Role of 
Taxation in the Competitiveness of Russian Education Following Globalization and Digitalization Processes in the World Economy, Turismo-Estudos E Pratica, Sn. 2 (2020): Geplat: Caderno Suplementar, n. 2, março 2020. 